\title{
Clinical Significance of Serum YKL-40 and its Correlation with Serum IL6 and CRP in Breast Cancer Patients
}

\author{
Enas A. Elkhouly ${ }^{1}$, Dalia. H. Abou-Elela ${ }^{2}$, Tamer. F. Abdel-Aziz ${ }^{3}$ \\ ${ }^{1}$ Department of Clinical Oncology and Nuclear Medicine, ${ }^{2}$ Clinical Pathology, ${ }^{3}$ General Surgery \\ Departments, Faculty of Medicine, Menoufia University, Egypt.
}

Background: Although most patients with early stage breast cancer treated with standard therapy have a high 5 year survival rate, biomarkers that can accurately predict relapse would be useful for monitoring patients most at risk for recurrence. One of these biomarkers is YKL-40 which is expressed in tumor tissue and serum. Cancer-related subclinical inflammation may be reflected by YKL-40 and C-reactive protein (CRP). Similarly, IL-6 was found to be associated with poor clinical outcomes in breast cancer. Our aim was to test the clinical significance of serum YKL-40 in breast cancer patients and to compare it to that of CRP and IL-6.

Patients and Methods: The study was conducted on 39 patients with breast cancer (13 patients early, 21 patients locally advanced, and 5 patients were metastatic breast cancer) and 12 controls. Samples to measure YKL-40, CRP and IL-6 from breast cancer patients were collected before starting anti-cancer treatment.

Results: There is a significant difference for YKL-40 $(P=0.001)$, IL6 $(P=0.001)$ and CRP $(P=0.02)$ between cases and controls. Comparing the diagnostic value of the three biomarkers between patients and controls, the area under the curve (AUC) was 0.92 in case of YKL-40 compared to 0.81 in IL-6 and 0.72 in CRP suggesting that YKL-40 is more accurate than both other tests. Similarly, comparing early to advanced stage showed that the AUC was 0.95 in case of YKL-40 compared to 0.86 in IL-6 and 0.66 in CRP. There was a significant association between CRP and tumor size $(P=0.049)$ and between IL6 and lymph node metastases $(P=0.001)$. Regarding YKL-40, there was a significant association between its level and both tumor size $(P=0.04)$ and disease stage $(P=0.03)$.

Conclusion: In conclusion, our study shows the significantly elevated serum YKL-40 level in breast cancer patients compared to healthy controls. Prospective investigations are needed to evaluate YKL-40 as a biomarker and to understand the molecular mechanisms that underlie the correlation between the YKL-40 elevated levels and breast cancer.

Key words: Breast cancer, YKL-40, IL6, CRP.

Corresponding Author: Enas Abou Bakr Elkhouly

E-mail: enasaboubaker6@hotmail.com

\section{INTRODUCTION}

Breast cancer is the most frequently diagnosed cancer in women and globally is the leading cause of cancer death in females ${ }^{1}$. Although most patients with early stage breast cancer are treated with standard therapy (surgery, chemotherapy, and/or radiation) and have a 5 year survival rate of $95 \%$, biomarkers that can accurately predict relapse would be useful for monitoring patients most at-risk for recurrence.

One promising biomarker for predicting risk breast cancer relapse is YKL-40, also called human cartilage glycoprotein-39 (HC gp-39) and chitinase 3-like 1. YKL40 is expressed in tumor tissue and serum². YKL-40 is a member of family 18 glycosyl-hydrolases, although no enzymatic activity has been detected. YKL-40 is a $40 \mathrm{kDa}$ heparin- and chitin-binding glycoprotein also known as human cartilage glycoprotein 39 (HC-gp39), 38-kDa heparin-binding glycoprotein or chitinase-3-like protein 1 (CHI3L1). The abbreviation YKL-40 is based on the one letter code for the first three N-terminal amino acids, tyrosine (Y), lysine $(\mathrm{K})$ and leucine $(\mathrm{L})$ and the apparent molecular weight of YKL-40. The YKL-40 gene consists of 10 exons located within $8 \mathrm{~kb}$ of DNA on human chromosome 1q32.1.

YKL-40 plays a role in inflammation, remodeling of extracellular matrix, regulation of cell proliferation, stimulation of angiogenesis, and protection against apoptosis ${ }^{4}$ YKL-40 and C-reactive protein (CRP) are biomarkers that may reflect cancer-related subclinical inflammation ${ }^{5}$. In addition, YKL-40 serum concentrations were higher in women with precancerous lesions than healthy controls ${ }^{6}$.

IL6 is a multi-poetic cytokine that induces the growth and differentiation of immune cells, the production and expression of other cytokines and acute phase protein synthesis. Additionally, it exerts several effects on cancer cell and activates the Rho protein which is associated with cell-cell adhesion and invasion 


Vol. 10 | No. 3-4 $2014 \quad$ Enas Abou Bakr et al

in malignancy. These factors together increase the aggressiveness of the tumor. It has been indicated that IL6 level increase with the increase of aggressiveness of tumors and advancement of their stage. It had been argued that IL6 may be secreted by cancer cell; however, its source is not clear ${ }^{7}$. It is produced by a diverse number of cell populations, most of which can localize to the breast tumor microenvironment. Excessive IL6 has been demonstrated in primary breast tumors and breast cancer patient sera and is associated with poor clinical outcomes in breast cancer ${ }^{8}$.

The aim of the present study was to determine the association between serum YKL-40 levels and breast cancer of different stages, and to compare its clinical relevance to that of CRP and IL6 in breast cancer patients.

\section{SUBJECTS AND METHODS}

\section{Patients'selection}

The present study was carried out at the Clinical Pathology Department in collaboration with General Surgery Department, and Clinical Oncology Department, Faculty of Medicine, Menoufia University in the period between April 2010 \& May 2013. The study was conducted on 51 females; the control group consisted of 12 healthy female volunteers without cancer or joint, liver, metabolic, or endocrine diseases. Clinical and routine hematological, biochemical and coagulation tests were performed to assess their health status.

The target group consisted of 39 patients with breast cancer of different stages (13 early stage, 21 locally advanced, and 5 metastatic). Informed written consent was obtained from all examined individuals.

Before being enrolled in the study, routine chest X-ray, breast mammography and abdominal ultrasonography were performed. Criteria for exclusion from the study were as follows: inflammatory breast cancer, pre-existing treatment or recurrence of the disease and the presence of diseases that cause an increase in plasma YKL-40 (e.g. liver disease, arthritis, and other cancers).

\section{Laboratory Methods}

Sampling: under complete aseptic conditions, $8 \mathrm{ml}$ of venous blood were collected in two sterile plain tubes and left to clot for 30 minutes then serum was divided into three aliquots, two kept immediately at $-20{ }^{\circ} \mathrm{C}$ for further determination of YKL-40 and IL- 6 and the third one was used for immediate assay of CRP. Blood samples were collected before starting anti-cancer treatment (surgery in early breast cancer patients, neo-adjuvant chemotherapy in locally advanced patients and chemotherapy/hormonal therapy in metastatic breast cancer patients).
Detection of CRP: CRP was determined using the (Orion Diagnostica Turbox assay, Finland) which is a liquid-phase immune-precipitation assay with nephelometric end-point detection. Antiserum to CRP is diluted in buffer and added to an aliquot of patient serum. The light scattering caused by antigen-antibody complexes is measured after incubation. The resulting light scattering is directly proportional to the CRP concentration in the sample.

Detection of Serum IL6 by ELISA: IL 6 was measured by (Orgenium Laboratories, AviBion humanIL -6 ELISA kit, Finland). The assay employs an antibody specific for human IL-6 coated on a 96- well plate. Standers, samples and biotinylated anti-human IL-6 are pipette into the wells and IL-6 present in a sample is captured by the antibody immobilized to the wells and by the biotinylated IL- 6 specific detection antibody. After washing away unbound biotinylated antibody, HRP-conjugated Streptavidin is pippeted to the wells. The wells are again washed. Following this second wash step, TMB substrate solution is added to wells, resulting in color development proportional to the amount IL-6 bound. The stop solution changes the color from blue to yellow and the intensity of the color is measured at 450 nm.

Detection of Serum YKL-40 by ELISA: Also YKL-40 was measured by ELISA (My Biosource USA). The kit uses a double antibody sandwich enzyme linked immune-sorbent assay (ELISA) to assay the level of Human Chitinase3like Protein1 (YKL40) in samples. Add Chitinase 3 like Protein (YKL 40) to monoclonal antibody Enzyme well which is precoated with Human Chitinase3like Protein 1 (YKL40) monoclonal antibody, incubation; then, add Chitinase 3 like Protein 1 (YKL40) antibodies labeled with biotin, and combined with Streptavidin HRP to form immune complex; then carry out incubation and washing again to remove the uncombined enzyme. Then add Chromogen Solution $\mathrm{A}, \mathrm{B}$, the color of the liquid changes into the blue and at the effect of acid, the color finally becomes yellow. The chroma of color and the concentration of the Human Substance Chitinase 3 like Protein 1 (YKL40) of sample were positively correlated and the intensity of the color is measured at $450 \mathrm{~nm}$.

\section{Statistical analysis}

SPSS software (version 17; SPSS Inc., Chicago, IL, USA) was used for statistical analysis. Descriptive statistics in the form of mean and standard deviation for parametric data) were used and value of the skewed parameters was expressed as median and inter-quartile range (IQR). For significance tests we used the student ${ }^{\circ} \mathrm{s}$ $\mathrm{t}$ test for comparison between two independent mean groups for parametric data and Mann-Whitney (U) test 
for statistical comparison between two sets of data if one or both of them have a skewed distribution. Evaluation of the performance was done using the sensitivity, specificity, positive predicative value, negative predicative value, accuracy and ROC curve. The significance level was set at 0.05 or less.

\section{RESULTS}

There was a significant difference for YKL-40 $(P=0.001)$, IL6 $(P=0.001)$ and CRP $(P=0.02)$ between cases and controls (Table 1).

Descriptive statistics of clinical characteristics of breast cancer patients showed that the median tumor size was $4.3 \mathrm{~cm} .64 .1 \%$ of cases were between 4060 - years with only $10.3 \%<40$ years and $25.6 \%>60$ years. The breast cancer stage was II in $33.3 \%$ of patients, III in $53.8 \%$ and IV in $12.8 \%$ (Table 2 ).

The Receiver Operator Characteristics (Roc) curve which compares the diagnostic value of the three markers between control and breast cancer groups shows that the area under the curve (AUC) which represents the overall accuracy of the test was 0.92 in case of YKL-40 while it was 0.81 in IL-6 and 0.72 in CRP (Figure. 1 and Table 3).

The ROC curve compares the diagnostic value of the three markers between early and advanced breast cancer groups and the above graph shows that AUC was 0.95 in case of YKL-40 while it was 0.86 in IL-6 and 0.66 in (Figure. 2 and Table 4).

There was no significant association between CRP measured values and the clinical risk factors except tumor size $(P=0.049)$ (Table 5).

There was no significant association between IL6 measured values and the clinical risk factors except lymph node metastases $(P=0.001)$ (Table 6).

There was no significant association between YKL40 measured values and the clinical risk factors except for tumor size $(P=0.04)$ and disease stage $(P=0.03)$ (Table 7).

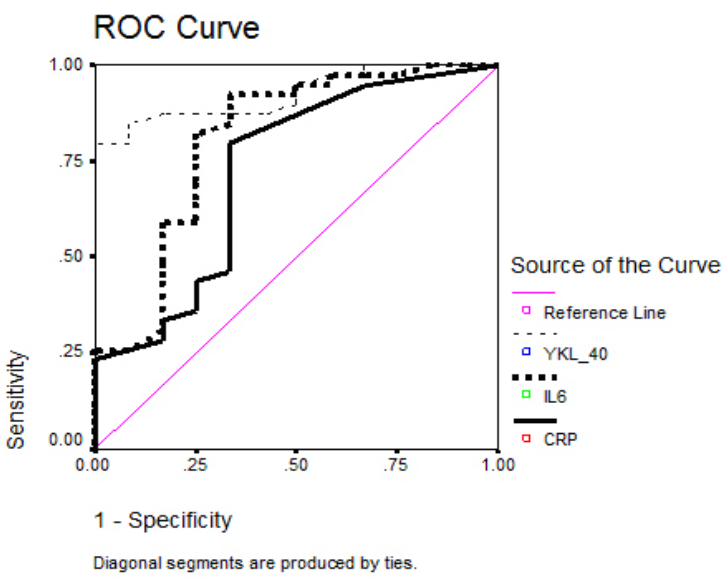

Figure. 1: ROC curve of CRP, IL-6 and YKL-40 to differentiate between cases and controls.

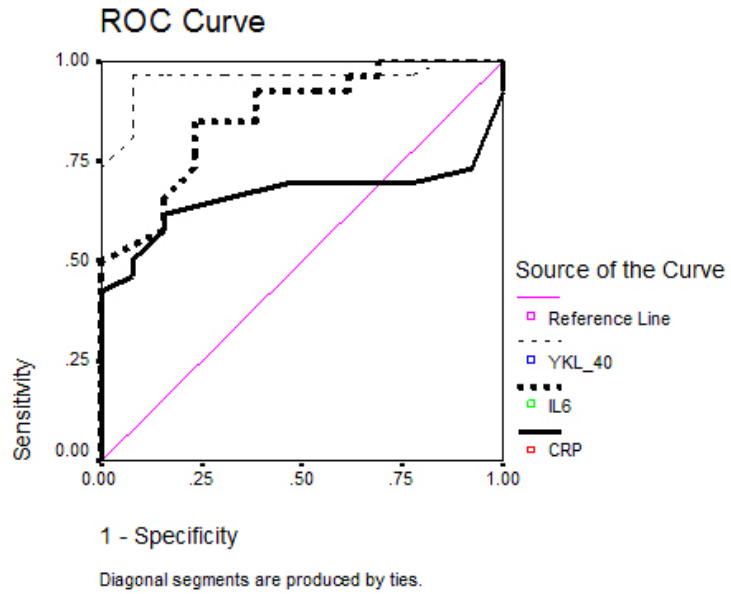

Figure. 2: ROC curve of CRP between early and advanced cases. 
Kasr-El-Aini Journal Of Clinical Oncology And Nuclear Medicine

Table 1: Comparison of age and measured markers between cases and controls.

\begin{tabular}{|c|c|c|c|c|}
\hline & \multicolumn{2}{|c|}{ Study group } & \multirow[b]{2}{*}{ Mann Whitney U test } & \multirow[b]{2}{*}{$P$ value } \\
\hline & $\begin{array}{c}\text { Case } \\
(N=39)\end{array}$ & $\begin{array}{l}\text { Control } \\
(N=12)\end{array}$ & & \\
\hline \multicolumn{5}{|l|}{ Age } \\
\hline $\mathrm{X} \pm \mathrm{SD}$ & $51.95 \pm 11.64$ & $31.58 \pm 8.99$ & & \\
\hline Median & 53 & 30.5 & 4.34 & 0.001 \\
\hline Range & $21-80$ & $20-48$ & & \\
\hline \multicolumn{5}{|l|}{ CRP } \\
\hline $\mathrm{X} \pm \mathrm{SD}$ & $12.0 \pm 11.66$ & $5.92 \pm 3.78$ & & \\
\hline Median & 7 & 4 & 2.34 & 0.02 \\
\hline Range & $3-53$ & $3-13$ & & \\
\hline \multicolumn{5}{|l|}{ IL 6} \\
\hline $\mathrm{X} \pm \mathrm{SD}$ & $20.72 \pm 9.31$ & $10.33 \pm 7.51$ & & \\
\hline Median & 18 & 9.5 & 3.20 & 0.001 \\
\hline Range & $4.5-45$ & $2.5-24$ & & \\
\hline \multicolumn{5}{|l|}{ YKL-40 } \\
\hline $\mathrm{X} \pm \mathrm{SD}$ & $70.02 \pm 20.24$ & $34.83 \pm 8.12$ & & \\
\hline Median & 75 & 37 & 4.41 & 0.001 \\
\hline Range & $30-100$ & $24-48$ & & \\
\hline
\end{tabular}

Table 2: Clinical characteristics of 39 patients with breast cancer.

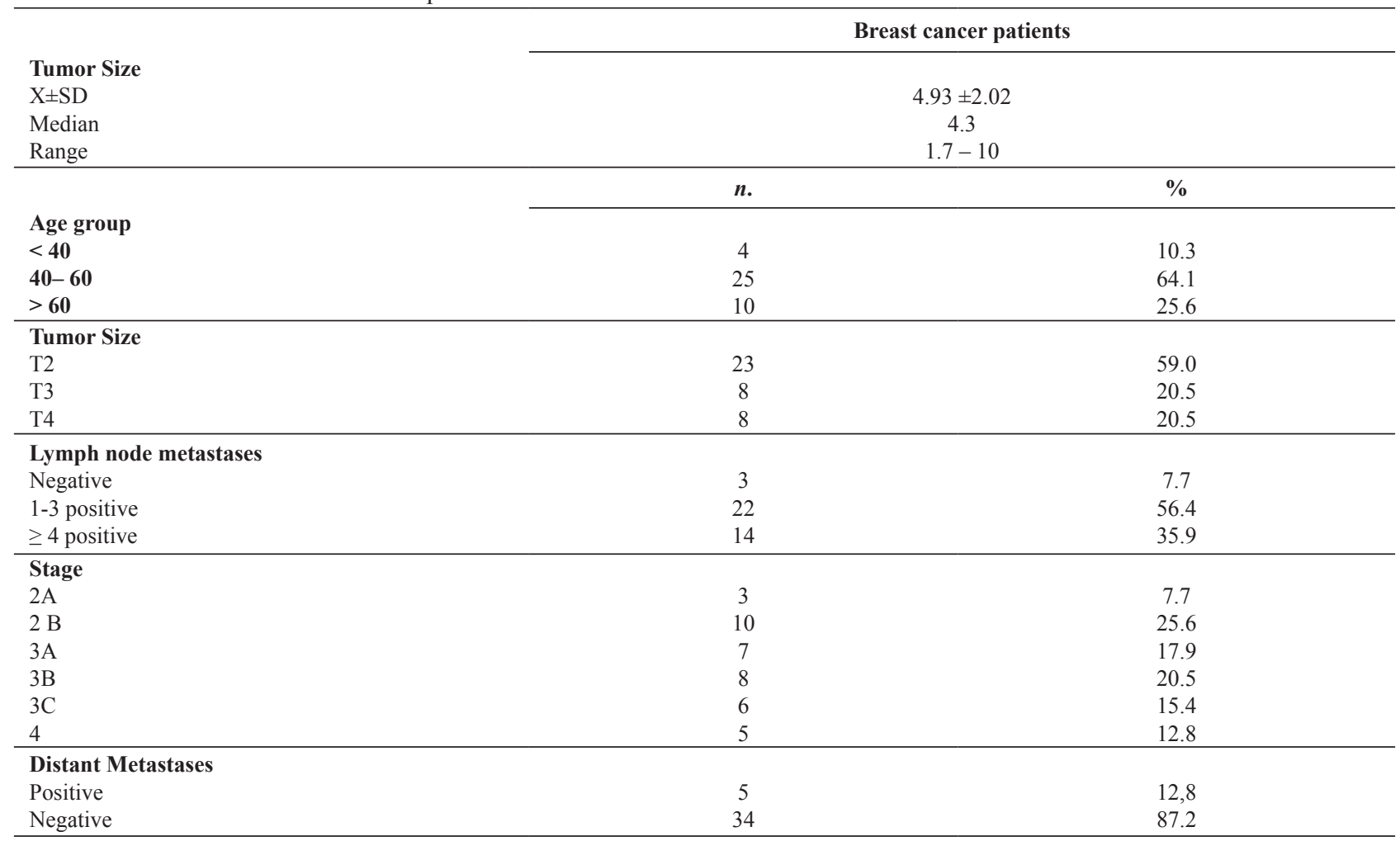

Table 3: Ability of CRP, IL-6 and YKL-40 in differentiating breast cancer cases from controls.

\begin{tabular}{|c|c|c|c|}
\hline & \multicolumn{3}{|c|}{ The studied parameters } \\
\hline & CRP & IL-6 & YKL-40 \\
\hline Cut off value & 4.5 & 12.25 & 41.5 \\
\hline Area under the curve(AUC) & $\begin{array}{c}0.72 \\
(0.55-0.90)\end{array}$ & $\begin{array}{c}0.81 \\
(0.65-0.97)\end{array}$ & $\begin{array}{c}0.92 \\
(0.85-0.99)\end{array}$ \\
\hline$P$ value & 0.02 & 0.001 & $\frac{10.05-001}{<0.001}$ \\
\hline Sensitivity & $79.5 \%$ & $82.1 \%$ & $87.2 \%$ \\
\hline Specificity & $66.7 \%$ & $75.0 \%$ & $83.3 \%$ \\
\hline Positive predictive value & $88.6 \%$ & $91.4 \%$ & 94.4 \\
\hline Negative predictive value & $50 \%$ & $56.3 \%$ & 66.7 \\
\hline Accuracy of the test & $76.5 \%$ & $80.4 \%$ & 86.3 \\
\hline
\end{tabular}


Kasr-El-Aini Journal Of Clinical Oncology And Nuclear Medicine

Vol. 10 | No. 3-4 2014

Serum YKL-40 in Breast Cancer

Table 4: Ability of CRP, IL-6 and YKL-40 in differentiating early breast cancer cases from advanced cases.

\begin{tabular}{lccc}
\hline & \multicolumn{3}{c}{ The studied parameters } \\
\cline { 2 - 4 } Cut off value & CRP & IL-6 & YKL-40 \\
\hline Area under the curve(AUC) & 6.5 & 17.5 & 57.0 \\
\hline P value & 0.66 & 0.86 & 0.95 \\
\hline Sensitivity & $0.49-0.83)$ & $(0.74-0.98)$ & $<0.89-1.02)$ \\
\hline Specificity & 0.10 & $<0.001$ & 86.2 \\
\hline Positive predictive value & 69.2 & 84.6 & 84.6 \\
\hline Negative predictive value & 53.8 & 76.1 & $\mathbf{9 2 . 6}$ \\
\hline Accuracy of the test & $\mathbf{7 5}$ & 88.0 & 91.7 \\
\hline
\end{tabular}

Table 5: Correlation between CRP and risk factors.

\begin{tabular}{|c|c|c|c|c|c|c|}
\hline & \multicolumn{4}{|c|}{ CRP } & \multirow[b]{2}{*}{ Mann Whitney U test } & \multirow[b]{2}{*}{$P$ value } \\
\hline & \multicolumn{2}{|c|}{$\begin{array}{c}\leq 5 \\
(N=11)\end{array}$} & \multicolumn{2}{|c|}{$\begin{array}{c}>5 \\
(N=28)\end{array}$} & & \\
\hline \multicolumn{7}{|l|}{ Age } \\
\hline $\mathrm{X} \pm \mathrm{SD}$ & \multirow{2}{*}{\multicolumn{2}{|c|}{$\begin{array}{c}56.27 \pm 12.22 \\
39-80\end{array}$}} & \multicolumn{2}{|c|}{$\begin{array}{c}50.25 \pm 11.16 \\
21-72\end{array}$} & 1.16 & 0.25 \\
\hline Range & & $39-80$ & \multicolumn{2}{|c|}{$21-72$} & & \\
\hline \multicolumn{7}{|l|}{ Tumor size } \\
\hline $\mathrm{X} \pm \mathrm{SD}$ & \multirow{2}{*}{\multicolumn{2}{|c|}{$\begin{array}{c}5.04 \pm 1.66 \\
2.5-7.5\end{array}$}} & \multirow{2}{*}{\multicolumn{2}{|c|}{$\begin{array}{c}4.88 \pm 2.17 \\
1.7-10\end{array}$}} & 0.52 & 0.61 \\
\hline \multirow[t]{2}{*}{ Range } & & & & & & \\
\hline & No & $\%$ & No & $\%$ & $\mathbf{X}^{2}$ & \\
\hline \multicolumn{7}{|l|}{ Age group } \\
\hline$<40$ & 1 & 9.1 & 6 & 21.4 & 1.37 & 0.51 \\
\hline $40-60$ & 6 & 54.5 & 16 & 57.1 & & \\
\hline$>60$ & 4 & 36.4 & 6 & 21.4 & & \\
\hline \multicolumn{7}{|l|}{ Tumor size } \\
\hline $\mathrm{T} 2$ & 4 & 36.4 & 19 & 67.9 & 6.01 & 0.049 \\
\hline T3 & 2 & 18.2 & 6 & 21.4 & & \\
\hline $\mathrm{T} 4$ & 5 & 45.5 & 3 & 10.7 & & \\
\hline \multicolumn{7}{|c|}{ Lymph node metastases } \\
\hline Negative & 0 & 0.0 & 3 & 10.7 & 4.27 & 0.12 \\
\hline $1-3$ positive & 9 & 81.8 & 13 & 46.4 & & \\
\hline$\geq 4$ positive & 2 & 18.2 & 12 & 42.9 & & \\
\hline \multicolumn{7}{|l|}{ Stage } \\
\hline Early & 3 & 27.3 & 10 & 35.7 & $0.25^{*}$ & 0.72 \\
\hline Advanced & 8 & 72.7 & 8 & 64.3 & & \\
\hline \multicolumn{7}{|c|}{ Distant metastases } \\
\hline Positive & 0 & 0.0 & 5 & 17.9 & $2.25^{*}$ & 0.30 \\
\hline Negative & 11 & 100 & 23 & 82.1 & & \\
\hline
\end{tabular}

\footnotetext{
$*$ Fisher's Exact test
} 
Table 6: Correlation between IL6 and risk factors.

\begin{tabular}{|c|c|c|c|c|c|c|}
\hline & \multicolumn{4}{|c|}{ IL6 } & \multirow{2}{*}{ Mann Whitney U test } & \multirow{2}{*}{$P$ value } \\
\hline & \multicolumn{2}{|c|}{$\begin{array}{c}\leq 7 \\
(N=2)\end{array}$} & \multicolumn{2}{|c|}{$\begin{array}{c}>7 \\
(N=37)\end{array}$} & & \\
\hline \multicolumn{7}{|l|}{ Age } \\
\hline $\mathrm{X} \pm \mathrm{SD}$ & \multirow{2}{*}{\multicolumn{2}{|c|}{$\begin{array}{c}39.5 \pm 6.36 \\
35-44\end{array}$}} & \multirow{2}{*}{\multicolumn{2}{|c|}{$\begin{array}{c}52.62 \pm 11.52 \\
21-80\end{array}$}} & \multirow{2}{*}{1.72} & \multirow{2}{*}{0.08} \\
\hline Range & & & & & & \\
\hline \multicolumn{7}{|l|}{ Tumor size } \\
\hline $\mathrm{X} \pm \mathrm{SD}$ & \multirow{2}{*}{\multicolumn{2}{|c|}{$\begin{array}{c}3.35 \pm 2.33 \\
1.7-5\end{array}$}} & \multirow{2}{*}{\multicolumn{2}{|c|}{$\begin{array}{l}5.02 \pm 2.0 \\
2.5-10\end{array}$}} & \multirow{2}{*}{0.96} & \multirow{3}{*}{0.34} \\
\hline Range & & & & & & \\
\hline & No & $\%$ & No & $\%$ & $\mathbf{X}^{2}$ & \\
\hline \multicolumn{7}{|l|}{ Age group } \\
\hline$<40$ & 1 & 50.0 & 6 & 16.2 & \multirow{3}{*}{1.76} & \multirow{3}{*}{0.41} \\
\hline $40-60$ & 1 & 50.0 & 21 & 56.8 & & \\
\hline$>60$ & 0 & 0.0 & 10 & 27.0 & & \\
\hline \multicolumn{7}{|l|}{ Tumor size } \\
\hline $\mathrm{T} 2$ & 2 & 100 & 21 & 56.8 & \multirow{3}{*}{1.47} & \multirow{3}{*}{0.48} \\
\hline T3 & 0 & 0.0 & 8 & 21.6 & & \\
\hline $\mathrm{T} 4$ & 0 & 0.0 & 8 & 21.6 & & \\
\hline \multicolumn{7}{|c|}{ Lymph node metastases } \\
\hline Negative & 2 & 100 & 1 & 2.7 & \multirow{3}{*}{25.3} & \multirow{3}{*}{0.001} \\
\hline 1-3 positive & 0 & 0.0 & 22 & 59.5 & & \\
\hline$\geq 4$ positive & 0 & 0.0 & 14 & 37.8 & & \\
\hline \multicolumn{7}{|l|}{ Stage } \\
\hline Early & 2 & 100 & 11 & 29.7 & \multirow{2}{*}{$4.22 *$} & \multirow{2}{*}{0.10} \\
\hline Advanced & 0 & 0.0 & 26 & 70.3 & & \\
\hline \multicolumn{7}{|c|}{ Distant metastases } \\
\hline Positive & 0 & 0.0 & 5 & 13.5 & \multirow{2}{*}{$0.31 *$} & \multirow{2}{*}{1.0} \\
\hline Negative & 2 & 100 & 32 & 86.5 & & \\
\hline
\end{tabular}

* = Fisher's Exact test

Table 7: Correlation between YKL and risk factors.

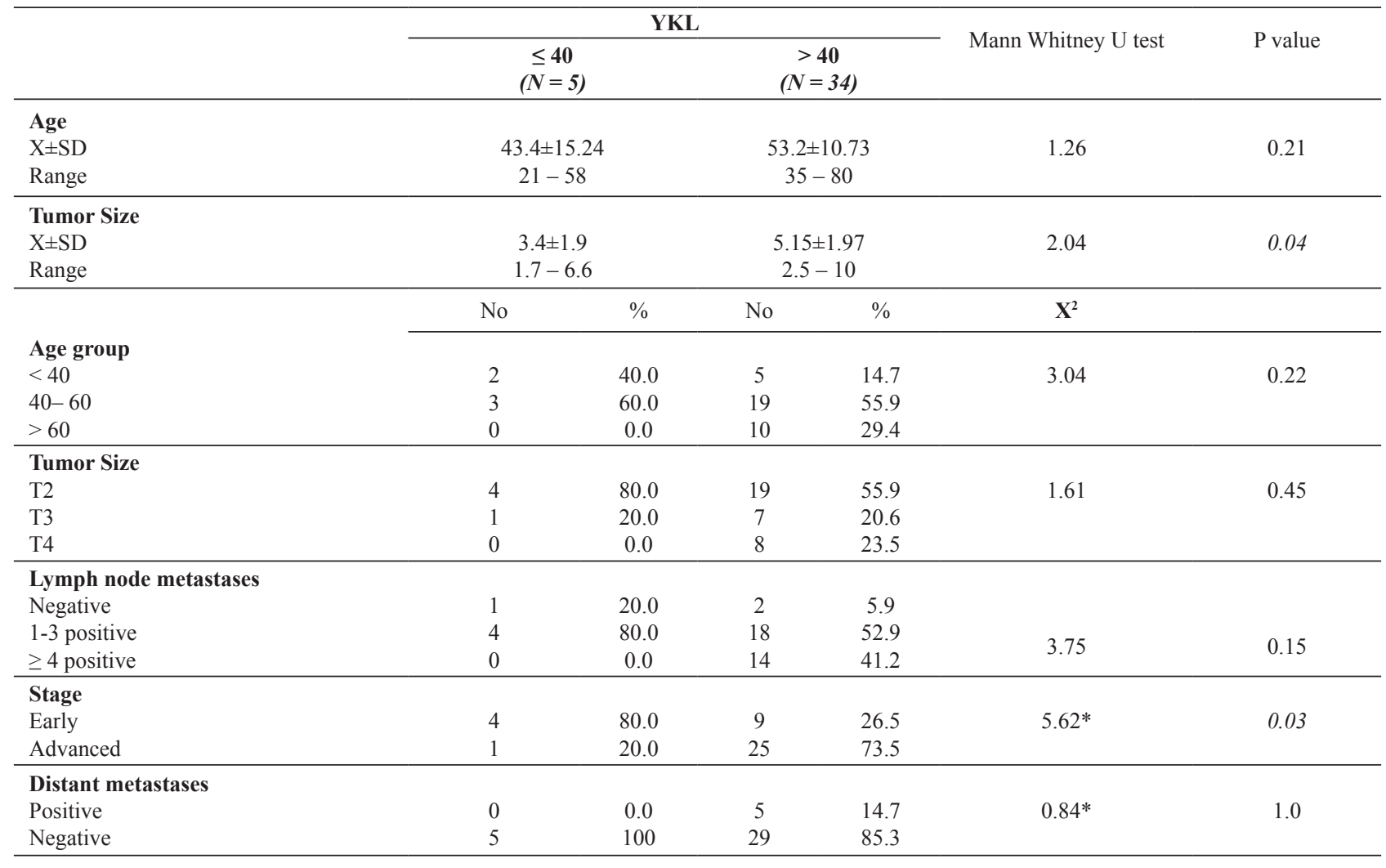




\section{DISCUSSION}

Breast cancer is the most common cancer worldwide ${ }^{9}$ It represents $28.2 \%$ of all female malignancies ${ }^{10}$.

YKL-40 is secreted by activated macrophages and macrophages during late stage of differentiation ${ }^{6}$ neutrophil ${ }^{11}$ and vascular smooth muscle cells ${ }^{12}$.

The concentration of YKL-40 increases in patients by more than $25 \%$ following an inflammatory stimulus and regarded as an acute phase protein ${ }^{15}$. It is emerging as a new biomarker of severe disease activity and poor prognosis in patients with diseases related to the degree of inflammation, pathological tissue remodeling, and ongoing fibrosis such as rheumatoid arthritis, inflammatory bowel disease, ischemic cardiovascular disease, chronic obstructive pulmonary disease, diabetes, and cancer ${ }^{16}$. YKL-40 facilitates cell attachment and migration of vascular endothelial cells, which is an indication that the protein may function in angiogenesis ${ }^{14}$.

ROC curve analysis was applied to assess the diagnostic utility of YKL-40 in discriminating breast cancer patients from the healthy control group. It was found that the best diagnostic cutoff level for YKL-40 was $41.5 \mathrm{ng} / \mathrm{ml}$. This cut-off value had a diagnostic sensitivity of $87.2 \%$, specificity of $83.3 \%$, negative predicative value of $66.7 \%$, positive predicative value of $94.4 \%$ and efficiency of $86.3 \%$. In case of IL-6, when ROC curve analysis was applied to assess its diagnostic utility in discriminating breast cancer patients from the healthy control group. It was found that the best diagnostic cutoff level for IL-6 was $11.75 \mathrm{ng} / \mathrm{ml}$. This cut-off value had $82.1 \%$ sensitivity, $75 \%$ specificity, $56.3 \%$ negative predicative value, $91.4 \%$ positive predicative value and $80.4 \%$ efficiency. When ROC analysis was applied to assess the diagnostic utility of CRP in discriminating breast cancer patients from the healthy control group, it was found that the best diagnostic cutoff level is $4.5 \mathrm{ng} /$ $\mathrm{ml}$. This cut-off value had a diagnostic $79.5 \%$ sensitivity, $66.7 \%$ specificity, $50 \%$ negative predicative value, $88.6 \%$ positive predicative value and $76.5 \%$ efficiency. These results suggest that YKL-40 is more accurate than CRP and IL-6.

This study showed that the level of YKL-40 was significantly increased in breast cancer patients when compared to healthy control patients. This result agreed with Yamac et $\mathrm{al}^{17}$ who demonstrated that the median serum YKL-40 concentration in patients with locally advanced breast cancer was $149.5 \mathrm{ug} / \mathrm{ml}$ and it was higher than levels observed in healthy female controls. It was suggested that YKL-40 may be a useful prognostic indicator of outcome for patients with locally advanced breast cancer. In addition, Kazakova et $\mathrm{al}^{18}$ study revealed that the mean value 41.11 (2059-) ng/ml of serum YKL-
40 in healthy subjects. The median serum concentration of YKL-40 in patients with breast carcinoma was 100.27 (36169-) ng/ml and it was significantly higher compared to the level in women with fibro-adenoma 44.58 (2287-) $\mathrm{ng} / \mathrm{ml}(P<0.001)$. Kazakova et al., study show that serum YKL-40 level in breast carcinoma is significantly higher than the concentration in healthy controls.

\section{CONCLUSION}

Our study shows the significantly elevated serum YKL-40 level in breast carcinoma compared to healthy controls and higher YKL-40 expression was significantly associated with advanced cases (Stage III and Stage IV) which reflect a poorer prognosis. Understanding the molecular mechanisms that underlie the correlation between the YKL-40 expression and breast cancer outcomes may provide novel targets for therapy.

Disclosure: the authors have no conflict of interest to declare.

\section{REFERENCE}

1. American Cancer Society, 2012: Cancer facts and Figures, Atlanta, GA: American Cancer Society. http://www.cancer.org/research/cancerfactsfigures/ acspc-031941.

2. Kim MJ, Park BW, Lim JB, et al. Axillary lymph node metastasis: CA15.3 and carcino-embryonic antigen concentration in fine-needle aspirate for preoperative diagnosis in patients with breast cancer. Radiology. 2010;254:691-697.

3. Shackelton LM, Mann DM, and Millis AJ. Identification of a 38-kDa heparin-binding glycoprotein (gp38k) in differentiating vascular smooth muscle cells as a member of a group of proteins associated with tissue remodeling. J Biol Chem. 1995;270:13076-13083.

4. Stawerski P, Wagrowska-Danilewicz M, StasikowskaKanicka O, et al. Increased tissue immunoexpression of YKL-40 protein in high grade serous ovarian cancers. Pathol Res Pract. 2011;207:573-576.

5. Allin KH, Bojesen SE, Johansen JS, et al. Cancer risk by combined levels of YKL-40 and C-reactive protein in the general population. Br J Cancer. 2012; 106:199205.

6. Johansen JS, Stoltenberg M, Hansen M, et al. Serum YKL-40 concentrations in patients with rheumatoid arthritis: Relation to disease activity. Rheumatology (Oxford). 1999;38:618-626.

7. Ravishankatan $\mathrm{P}$ and Karunanithi R. Clinical significance of preoperative serum interleukin- 6 and $\mathrm{C}$-reactive protein level in breast cancer patients. World J Surg Oncol. 2011;9:18.

8. Sullivan NJ, Sasser AK, Axel AE, et al. Interleukin-6 induces an epithelial-mesenchymal transition phenotype 
in human breast cancer cells. Oncogene. 2009;28:29402947.

9. Liu Y, Gao C, Ding J, et al. Physiological factors and breast cancer risk in Jiangsu province of China. Asian Pac J Cancer Prev. 2011;12:787-790.

10. Sebova K, Zmetakova I, Bella V, et al. RASSF1A and CDH1 hypermethylathion as potential epi-markers in breast cancer. Cancer Biomark. 2011-2012;10:13-26.

11. Volck B, Price PA, Johansen JS, et al. YKL-40, a mammalian member of the chitinase family, is a matrix protein of specific granules in human neutrophils. Proc Assoc Am Physicians. 1998;110:351-360.

12. Malinda KM, Ponce L, Kleinman HK, et al. Gp38k, a protein synthesized by vascular smooth muscle cells, stimulates directional migration of human umbilical vein endothelial cells. Exp Cell Res. 1999;250:168-173.

13. Johansen JS, Olee T, Price PA, et al. Regulation of YKL-40 production by human articular chondrocytes. Arthritis Rheum. 2001;44:826-837.
14. Johansen JS, Jensen BV, Roslind A, et al. Serum YKL40, a new prognostic biomarker in cancer patients? Cancer Epidemiol Biomarkers Prev. 2006;15:194-202

15. Roslind A and Johansen JS. YKL-40: a novel marker shared by chronic inflammation and oncogenic transformation. Methods Mol Biol. 2009;511:159-184.

16. Güngen G, Ardic F, Findıkoğlu G, et al. The effect of mud pack therapy on serum YKL-40 and hsCRP levels in patients with knee osteoarthritis. Rheumatol Int. 2012;32:1235-1244.

17. Yamac D, Ozturk B, Coskun U, et al. Serum YKL-40 levels as a prognostic factor in patients with locally advanced breast cancer. Adv Ther. 2008;25: 801-809.

18. Kazakova M, Deneva T, Uzunova V, et al. YKL-40 in sera of breast tumor patients. J of IMAB. 2010;16:3-7. 